\title{
Evaluation of the effectiveness of dequalinium chloride vaginal tablets in aerobic vaginitis: A placebo-controlled study
}

\author{
Sibel Ejder Tekgunduz ${ }^{1}$, Ferit Saracoglu² \\ From ${ }^{1}$ Department of Obstetrics and Gynecology, Erzurum Training and Research City Hospital, Erzurum, Turkey, ${ }^{2}$ Femcare Women's Clinic, General \\ Director of Obstetrics and Gynecology Clinic, Ankara, Turkey
}

Correspondence to: Sibel Ejder Tekgunduz, Department of Obstetrics and Gynecology, Erzurum Training and Research City Hospital, Erzurum, Turkey. E-mail: sibeltekgndz@hotmail.com

Received - 26 March $2021 \quad$ Initial Review - 10 April 2021

Accepted - 09 July 2021

\section{ABSTRACT}

Background: Aerobic vaginitis is a disturbance of vaginal homeostasis caused by the colonization of enteric bacteria. They are not clinically well-defined and do not have standard treatment regimes. Hence, the present study was conducted to evaluate the effectiveness of dequalinium chloride topical vaginal administration in aerobic vaginitis in a placebo-controlled manner. Materials and Methods: This study was conducted in a placebo-controlled manner to demonstrate the effectiveness of vaginal $10 \mathrm{mg}$ dequalinium chloride. A total of 30 patients with different vaginal infections were included in the study. The patients included in the study were divided between the drug group and the placebo group and were treated with one vaginal tablet daily for 6 days. The total symptom score, which consists of the assessment of discharge, itching, and burning sensation, and the lactobacillus grade evaluated microscopically, was determined. Results: It was found that the effectiveness of dequalinium chloride was very high compared to placebo $(92 \%$ vs. $0 \%)$. The reproduction frequency in the first visit was statistically significantly lower in the drug group compared to the placebo group $(P<0.001)$. Conclusion: It was found that dequalinium chloride is effective for the treatment of aerobic vaginitis. However, studies containing a larger sample group, including the long-term effects (efficacy and side effects) of the drug, should be conducted to prove our conclusion.

Key words: Aerobic vaginitis, Dequalinium chloride, Vaginitis

$\mathrm{V}$ ulvovaginal infections are the most common cause of women to consult a doctor for professional help. The vaginal ecosystem is characterized by an endogenous microflora whose qualitative and quantitative combination can change due to endogenous and exogenous factors [1]. Any change in the vaginal ecosystem is a primary risk factor in the occurrence of three classic pathologies of the lower genital tract (candidiasis, trichomoniasis, and bacterial vaginosis) [2,3]. The diagnosis and treatment options of these pathologies are completely determined by the authorities, and other abnormal conditions of the vaginal ecosystem still need to be studied [4]. The term aerobic vaginitis was defined by Donders et al. as an abnormal vaginal flora condition, which cannot be defined as bacterial vaginosis, characterized by a yellow-colored, smelly discharge (KOH test negative) $\mathrm{pH}>5$, inflammation, and dyspareunia. In other words, aerobic vaginitis is a disturbance of vaginal homeostasis caused by the colonization of enteric bacteria [5].

Dequalinium chloride is an antiseptic agent which belongs to the class of quaternary ammonium compounds. This substance has a broad-spectrum antimicrobial effect, including Grampositive, Gram-negative bacteria, protozoa, and fungi. It shows its effect by causing damage to the cytoplasmic membrane [6]. Like other surface-acting compounds, the first effect of dequalinium chloride is to increase cell permeability and lead to loss of enzyme activity and cause cell death. The antimicrobial activity of dequalinium chloride was demonstrated by detecting a minimum inhibitory concentration (MIC) against many vaginal pathogens in vitro conditions. When $10 \mathrm{mg}$ dequalinium chloride was dissolved in about $2.5 \mathrm{ml}$ of vaginal fluid, the concentration of dequalinium chloride in the vaginal fluid was $4.000 \mathrm{mg} / \mathrm{l}$; this value was above the MIC value of all pathogenic microorganisms tested [7]. Dequalinium chloride was tested for all Staphylococcus, Streptococci, Enterococci, Listeria, Escherichia, Proteus, Gardnerella, Bacteroides, Prevotella, Porphyromonas, Candida, and Trichomonas species. Dequalinium chloride was effective in all microorganisms except Proteus mirabilis [8]. Treatment effectiveness and reliability of dequalinium chloride were demonstrated by clinical studies conducted over a period of 10 years of market experience. The fact that there was no resistance development to dequalinium chloride in microorganisms provides an advantage in terms of treatment activity in the clinical use of the drug $[9,10]$.

The current treatment of aerobic bacterial vaginal infections is clindamycin, hexetidine, kanamycin, or povidone-iodine but its success is limited $[9,10]$. Aerobic bacterial vaginal infections are conditions that are not clinically well-defined and do not 
have standard treatment regimes. Hence, the present study was conducted to evaluate the effectiveness of dequalinium chloride topical vaginal administration in aerobic vaginitis in a placebocontrolled manner.

\section{MATERIALS AND METHODS}

This study was conducted in the obstetrics and gynecology clinic of the research hospital in Turkey. The present study was conducted in a double-blind, placebo-controlled manner investigating the effectiveness and tolerability of $10 \mathrm{mg}$ dequalinium chloride (Fluomizin, Medinova AG®) vaginal tablets in aerobic vaginitis.

Among the patients admitted to our clinic, (a) women after menarche aged between 18 and 50 whose menopause did not start yet; (b) women with symptoms of an aerobic bacterial vaginal infection and with a total symptom score (TSS) of $\geq 5$; (c) women with disturbed vaginal microflora with Lactobacillus Grade (LBG) II; (d) existence of at least one vaginal culture positivity with the related bacteria (i.e., streptococci, enterococci, S. aureus, Pseudomonas, E. coli, and other enterobacteria); and (e) among fertile patients, those who used high effective birth control methods (implant, injectable, or combined oral contraceptive, intrauterine device, absence of sexual life, or vasectomized men) were included in the study.

Women with the (a) diagnosis of bacterial vaginosis and/or presence of clue cells; (b) diagnosis of vulvovaginal candidiasis based on clinical symptoms and/or microscopic examination; (c) pregnancy and lactation; (d) women with uterine bleeding (including menstruation, excluding the contact cervical bleeding during taking sample) or vaginal bleeding of unknown origin; (e) presence of genital malignancy, clinical presence or suspicion of sexually transmitted disease, and ulceration of the vulva, vagina, or cervix, and (f) presence of acute pelvic inflammatory disease were excluded from the study. Women that were using local or systemic antibiotics in the past 14 days and who had done vaginal showering with soap or anionic substances in the past $48 \mathrm{~h}$ and/or during the study were also excluded from the study.

In the primer efficacy evaluation, clinical cure rate was measured based on the TSS (in case of no discharge $=0$, mild $=$ 1 , moderate $=2$, and severe $=3$; in case of no itching $=0$, mild $=$ 1 , moderate $=2$, and severe $=3$; and in case of no burning $=0$, mild $=1$, moderate $=2$, and severe $=3$ ) and LBG (Grade $1=$ Normal flora, Grade 2 = Disturbed flora, and Grade 3 = Abnormal flora) was used. The case was considered to be treated clinically when the patient's TSS was 2 or lower in the second control visit along with an LBG of 1.

A simple random sampling method was used in the study. Those who met the research criteria were included in the study. This research was carried out as a pilot study, therefore, a total of 30 patients who met all the criteria stated and had no problems with the follow-up were included in the study. Among the patients, 15 of them received the placebo, and 15 of them received the drug. The doctor who performed the examination was given a total of 30 boxes. The properties of the drugs used in the study are illustrated as Table 1. After the diagnosis, boxes containing unknown content were given to patients. The boxes were randomized based on the number list given to the polyclinic by randomizer.org. The patients came for the first control visit after 4-7 days, while they came for the second control visit after 3-4 weeks. As a criterion for a full recovery, the TSS was planned to be 2 and below, and LBG was planned to be 1 .

The patients with aerobic bacterial vaginal infection suspicion were examined to review the patient selection criteria determined. First, the TSS of the patients was viewed and those with $\geq 5$ were determined. Vaginal secretion was taken from the posterior fornix using a spatula and spread over a microscope slide. A drop of normal saline was dripped, covered by a lamel, and examined microscopically in $\times 400$ measuring magnifier. For the exclusion of bacterial vaginosis, in accordance with the Amsel criteria, the presence of clue cell in the preparate prepared, the presence of fish odor due to excretion of amine when $10 \%$ potassium was dropped in vaginal secretion was evaluated, $\mathrm{pH}$ measurement was performed in the upper $1 / 3$ of vagina's lateral wall, the presence of discharge and odor specific to vaginosis was evaluated.

The sample taken from the patient's discharge from posterior fornix by sterile swab was taken to the microbiology laboratory in a BTR sterile Stuart transport swab LOT 00005, then Gram coloration was performed from these samples with direct spread and these preparates were examined. The samples were cultivated in human blood agar, EMB agar, and chocolate agar and examined after being kept in $37^{\circ} \mathrm{C}$ incubators for $24 \mathrm{~h}$. In the first examination of the patients, swab samples were taken from the endocervical channel using expiry 2012-2012 lot no. M2316AAA sterile swab, to screen the sexually transmitted diseases and were taken to the laboratory to study chlamydia PCR through COP AN UTM-RT MINI transport medium. The patients were checked for genital malignancies during the examination. A pregnancy test was done. Fever, pulse, and arterial blood pressure were checked among the vital signs. Patients' birth dates, latest period dates, number of pregnancies or births, methods for birth control, body weights, vaginal infection numbers from the past 12 months, bacterial vaginosis numbers from the past 2 years, disease history, and the use of regular drugs were questioned. After the initial evaluation of patients, those included in the study were given numbers from 1 to 30 . Study drugs numbered between 1 and 30 were given to patients. The patients were explained how to use them; they were asked to apply one tablet into the vagina before going to sleep every night for 6 days and to bring the drug boxes in the next follow-up. Patients were also given a study diary and told to fill it out during treatment. The first follow-up dates were determined within 4-7 days after the end of treatment.

The following procedures were applied to patients who came to the follow-up: The presence of criteria for exclusion from the study was considered as a result of the laboratory tests requested in the first meeting with the patients; the treatments received by the patients were recorded in addition to the treatment given within the study; effectiveness parameters of the treatment were evaluated (TSS, LBG, leukocyte count in microscopic examination 
Table 1: Characteristics of the investigated product and placebo

\begin{tabular}{llll}
\hline Name & Investigated product & Placebo \\
\cline { 2 - 2 } Dosage and form & Dequalinium chloride vaginal tablet (Fluomizin) & & Placebo vaginal tablet \\
\hline Manufacturer & Box containing six vaginal tablets (10 mg) & & $\begin{array}{l}\text { Box with six vaginal tablets containing } \\
\text { non-pharmaceutical substance } \\
\text { Product No. }\end{array}$ \\
Clinical study drug manufacturer & Medinova AG, Switzerland & Medinova AG, Switzerland \\
Imports and EU-distributor & 380016 & 380605 \\
Study drug product no & Losan Pharma Ltd., Germany & 2006125 & Ivers-Lee Ltd., Switzerland \\
\hline
\end{tabular}

of vaginal secretion, aerobic bacterial growth in vaginal culture, diagnosis of vulvovaginal candidiasis by clinical symptoms and/ or microscopic examination, diagnosis of bacterial vaginosis based on Amsel criteria, and global effectiveness assessment; the patient and researcher evaluated treatment effectiveness subjectively and used a 4-point measure containing very good, good, medium, and bad parameters); side effects were recorded, and tolerability was evaluated; drug boxes were taken back and their use status checked. A second follow-up was planned for 3-4 weeks after the end of treatment. The same procedure was followed for patients. The case was considered to be treated clinically when the patient's TSS was 2 or lower in the second control visit along with an LBG of 1.

\section{Statistical Analysis}

The data were analyzed using the SPSS 11.5 package program. Descriptive statistics were expressed as average \pm standard deviation for age, and the median formed nominal variables for TSC (minimum-maximum) was expressed as observation numbers and (\%). The significance of the difference between the placebo and the drug group in terms of mean age was evaluated by the Student's t-test and the significance of the difference in terms of TSC levels was evaluated by the Mann-Whitney U-test. The Friedman test was used to determine whether there was a significant change in TSC levels within the groups according to time. In case the Friedman test, statistics result was significant, the follow-up time that caused the significant difference was determined by the Wilcoxon sign test. In terms of recovery and reproduction frequency, Fisher's exact test was used in the comparisons between groups, McNemar test was used in comparisons within the groups. The results were considered statistically significant for $\mathrm{p}<0.05$.

\section{RESULTS}

Patients numbered 3, 8, 9, 26, 28, 29, and 30 were excluded from the study as their chlamydia PCR results were $(+)$ and were not included in the statistical analysis. The mean age of the placebo group was $32.7 \pm 9.7$ (years), while the mean age of the drug group was $35.9 \pm 7.8$ (years) $(\mathrm{p}=0.394)$ [Table 2]. The distribution of the reproduced microorganisms in the first and second visits before the treatment based on groups is shown in Table 3 .
There was a statistically significant change occurred in the TSS levels in the placebo group based on time $(\mathrm{p}=0.003)$ in the group who have completed their visits. The decrease in the TSS levels in the first and second visits was statistically significant compared to the time before treatment ( $\mathrm{p}=0.010$ and $\mathrm{p}=0.018$ ). There was a statistically significant change in the TSS levels in the drug group according to time $(\mathrm{p}<0.001)$. The decrease in the TSS levels in the first and second visits was statistically significant compared to the time before treatment $(\mathrm{p}=0.002$ and $\mathrm{p}=0.003$ ). There was a statistically significant difference between the first and the second visits in terms of TSS levels $(\mathrm{p}=0.048)$. The decrease in the TSS level compared to the time before the treatment in the first and second visits was significantly higher in the drug group compared to the placebo group $(\mathrm{p}<0.001$ and $\mathrm{p}=0.006$ ) [Table 4].

When the evaluation was made based on the cases with before treatment and first visit TSS follow-ups, there was not a significant difference between the before treatment and first visit TSS levels in the placebo group, while the decrease in the TSS level in the drug group in the first visit was statistically significant compared to the time before treatment $(\mathrm{p}=0.119$ and $\mathrm{p}=0.002$ ). While the TSS levels were similar between the groups before treatment, the TSS level in the first visit was significantly lower in the drug group compared to the placebo group $(\mathrm{p}=0.883$ and $\mathrm{p}<0.001)$. The decrease in the TSS level that occurred in the $1^{\text {st }}$ visit compared to the time before treatment was statistically high in the control group compared to the placebo group ( $\mathrm{p}<0.001)$ [Table 4].

When the cases whose visits were complete were evaluated, there was a statistically significant change in the LBG levels in the placebo group based on time $(\mathrm{p}=0.002)$. The decrease in the LBG score in the $2^{\text {nd }}$ visit compared to the time before treatment and the $2^{\text {nd }}$ visit compared to the $1^{\text {st }}$ visit showed a statistically significant difference $(\mathrm{p}=0.005$ and $\mathrm{p}=0.025)$. There was also a statistically significant change in the drug group according to time $(p<0.001)$. The decrease in the LBG levels in the first and second visits was statistically significant compared to the time before treatment $(p=0.002$ and $p<0.001)$. There was a statistically significant difference between the first and second visits in terms of LBG levels ( $\mathrm{p}=0.035)$. The LBG levels of the drug group were statistically and significantly lower compared to the placebo group in the first and second visits $(\mathrm{p}=0.009$, and $\mathrm{p}=0.002)$. The decrease level in the LBG level compared to the time before the treatment in the first and second visits was significantly higher 
Table 2: Total results of patients participating in the study

\begin{tabular}{|c|c|c|c|c|c|c|c|c|c|c|}
\hline No. & Basal & TSS & LBG & $1^{\text {st }}$ follow-up & TSS & LBG & $2^{\text {nd }}$ follow-up & TSS & LBG & Drug \\
\hline 1 & E. coli & 6 & 3 & Candida & 4 & 2 & S. agalactiae & 3 & 2 & 0 \\
\hline 2 & $\begin{array}{l}\text { Enterobacter } \\
\text { aerogenes }\end{array}$ & 7 & 3 & E. coli & 5 & 2 & Gardnerella & 4 & 2 & 0 \\
\hline 4 & E. coli & 7 & 3 & E. coli & 2 & 3 & No reproduction & 1 & 1 & 1 \\
\hline 5 & $\begin{array}{l}\text { Klebsiella } \\
\text { pneumoniae }\end{array}$ & 7 & 3 & No reproduction & 3 & 2 & Enterococci & 1 & 1 & 1 \\
\hline 6 & MRSA & 6 & 3 & No Reproduction & 2 & 2 & E. coli & 6 & 3 & 1 \\
\hline 7 & $\begin{array}{l}\text { B-Hemolytic } \\
\text { Streptococcus }\end{array}$ & 7 & 3 & No reproduction & 2 & 2 & No Reproduction & 2 & 1 & 1 \\
\hline 10 & S. haemolyticus & 6 & 3 & Gardnerella & 6 & 3 & S. aureus & 4 & 2 & 0 \\
\hline 11 & S. haemolyticus & 7 & 3 & S. haemolyticus & 5 & 3 & Coagulase Staphylococcus & 7 & 3 & 0 \\
\hline 12 & E. coli & 8 & 3 & $\begin{array}{l}\text { Klebsiella } \\
\text { pneumoniae }\end{array}$ & 2 & 2 & No reproduction & 0 & 1 & 1 \\
\hline 13 & E. coli & 9 & 3 & No reproduction & 2 & 1 & No reproduction & 1 & 1 & 1 \\
\hline 14 & E. coli & 7 & 3 & No reproduction & 3 & 2 & Gardnerella & 1 & 1 & 1 \\
\hline 15 & Enterococcifaecalis & 8 & 3 & $\begin{array}{l}\text { Klebsiella } \\
\text { pneumoniae }\end{array}$ & 5 & 3 & Klebsiella pneumoniae & 3 & 2 & 0 \\
\hline 16 & S. hominis & 9 & 3 & $\begin{array}{l}\text { B Strep+Coagulase } \\
\text { Staf/ }\end{array}$ & 6 & 2 & Coagulase Staphylococcus & 3 & 2 & 0 \\
\hline 17 & E. coli & 9 & 3 & E. coli & 7 & 3 & $\begin{array}{l}\text { Coagulase } \\
\text { Staphylococcus }+ \text { Candida }\end{array}$ & 5 & 2 & 0 \\
\hline 18 & E. coli & 6 & 3 & Klebsiella pneumoniae & 3 & 2 & No reproduction & 0 & 1 & 1 \\
\hline 19 & S. haemolyticus & 5 & 3 & No reproduction & 2 & 1 & No reproduction & 1 & 1 & 1 \\
\hline 20 & S. haemolyticus & 5 & 3 & Candida & 8 & 3 & No reproduction & 0 & 0 & 0 \\
\hline 21 & Proteus mirabilis & 6 & 3 & Gardnerella & 8 & 3 & No reproduction & 0 & 0 & 0 \\
\hline 22 & E. coli & 9 & 3 & E. coli & 6 & 3 & Gardnerella & 5 & 2 & 0 \\
\hline 23 & Enterococcifaecalis & 8 & 3 & Klebsiella pneumoniae & 5 & 2 & No reproduction & 2 & 1 & 1 \\
\hline 24 & $\begin{array}{l}\text { E. coli+Coagulase } \\
\text { Staph }\end{array}$ & 6 & 3 & E. coli & 5 & 3 & E. coli & 6 & 2 & 0 \\
\hline 25 & E. coli & 8 & 3 & No reproduction & 5 & 2 & No reproduction & 2 & 1 & 1 \\
\hline 27 & $\begin{array}{l}\text { E. coli+Coagulase } \\
\text { Staph }\end{array}$ & 8 & 3 & No reproduction & 4 & 1 & No reproduction & 2 & 1 & 1 \\
\hline
\end{tabular}

O=Placebo, 1 =Active drug

in the drug group compared to the placebo group ( $\mathrm{p}=0.009$ and $\mathrm{p}=0.002$ ). When the evaluation was made based on the cases just with before treatment and first visit TSS follow-ups, there was not a significant difference between the before treatment and first visit LBG levels in the placebo group, while the decrease in the LBG level in the drug group in the first visit was statistically significant compared to the time before treatment $(\mathrm{p}=0.083$ and $\mathrm{p}=0.002$ ). The $L B G$ level in the first visit was significantly lower in the drug group compared to the placebo group $(\mathrm{p}=0.003)$. The decrease in the LBG level that occurred in the $1^{\text {st }}$ visit compared to the time before treatment was statistically high in the control group compared to the placebo group ( $\mathrm{p}=0.003$ ) [Table 5].

According to the evaluation made based on 21 cases with complete before treatment, there was a statistically significant difference in the decrease in reproduction frequency in the drug group in the first and second visits compared to the time before treatment $(\mathrm{p}=0.008$ and $\mathrm{p}=0.004)$. The reproduction frequencies in the first and second visits between the groups showed a statistical significance, and the reproduction frequency in the drug group was lower compared to the placebo $(\mathrm{p}=0.005$ and $\mathrm{p}<0.001$ ) [Table 6].

Statistically significant difference was not present in terms of reproduction frequency between the before treatment and first visit in the placebo group according to the evaluation made based on 23 cases with complete before treatment and first visit followups. The decrease in the reproduction frequency in the before treatment and first visit in the drug group showed a statistically significant difference $(\mathrm{p}=0.008)$. The reproduction frequency in the first visit was statistically significantly lower in the drug group compared to the placebo group $(\mathrm{p}<0.001)$ [Table 7].

\section{DISCUSSION}

In the literature, there are very few studies conducted on the dequalinium chloride in vaginitis. A clinical study tested the effect and local tolerability of dequalinium chloride in 388 patients with vaginal infection, 274 of whom had bacterial vaginitis, and achieved success of $70-85 \%$ in the treatment made by vaginal 
Table 3: Distribution of the reproduced microorganisms in the first and second visits before the treatment based on groups

\begin{tabular}{|c|c|c|c|c|c|c|}
\hline \multirow[t]{2}{*}{ Reproduced microorganisms } & \multicolumn{2}{|c|}{ Placebo $(n=11)$} & \multicolumn{2}{|c|}{ Drug $(n=12)$} & \multicolumn{2}{|c|}{ Total $(n=23)$} \\
\hline & $n$ & $\%$ & $n$ & $\%$ & $n$ & $\%$ \\
\hline \multicolumn{7}{|l|}{ Before Treatment } \\
\hline B-hemolytic Streptococcus & - & - & 1 & 8.3 & 1 & 4.3 \\
\hline E. coli & 3 & 27.3 & 6 & 50.0 & 9 & 39.1 \\
\hline E. coli + Coagulase Staph & 1 & 9.1 & 1 & 8.3 & 2 & 8.7 \\
\hline Enterobacter aerogeries & 1 & 9.1 & - & - & 1 & 4.3 \\
\hline Enterococcus faecalis & 1 & 9.1 & 1 & 8.3 & 2 & 8.7 \\
\hline Klebsiella pneumoniae & - & - & 1 & 8.3 & 1 & 4.3 \\
\hline MRSA & - & - & 1 & 8.3 & 1 & 4.3 \\
\hline Proteus mirabilis & 1 & 9.1 & - & - & 1 & 4.3 \\
\hline S. haemolyticus & 3 & 27.3 & 1 & 8.3 & 4 & 17.4 \\
\hline S. hominis & 1 & 9.1 & - & - & 1 & 4.3 \\
\hline \multicolumn{7}{|l|}{$1^{\text {st }}$ visit } \\
\hline No reproduction & - & - & 8 & 66.7 & 8 & 34.8 \\
\hline B Strep+Coagulase Staf & 1 & 9.1 & - & - & 1 & 4.3 \\
\hline Candida & 2 & 18.2 & - & - & 2 & 8.7 \\
\hline E. coli & 4 & 36.4 & 1 & 83 & 5 & 21.7 \\
\hline Gardnerella & 2 & 18.2 & - & - & 2 & 8.7 \\
\hline Klebsiella pneumoniae & 1 & 9.1 & 3 & 25.0 & 4 & 17.4 \\
\hline S. haemolyticus & 1 & 9.1 & - & - & 1 & 4.3 \\
\hline \multicolumn{7}{|l|}{$2^{\text {nd }}$ visit } \\
\hline No reproduction & - & - & 9 & 75.0 & 9 & 42.9 \\
\hline E. coli & 1 & 11.1 & 1 & 83 & 2 & 9.5 \\
\hline Enterococci & - & - & 1 & 83 & 1 & 4.8 \\
\hline Gardnerella & 2 & 22.2 & 1 & 83 & 3 & 13.0 \\
\hline Klebsiella pneumoniae & 1 & 11.1 & - & - & 1 & 4.8 \\
\hline Coagulase-Staphylococcus & 2 & 22.2 & - & - & 2 & 9.5 \\
\hline Coagulase Staphylococcus + Candida & 1 & 11.1 & - & - & 1 & 4.8 \\
\hline S. aureus & 1 & 11.1 & - & - & 1 & 4.8 \\
\hline S. agalactiae & 1 & 11.1 & - & - & 1 & 4.8 \\
\hline
\end{tabular}

Table 4: The comparison of the groups in terms of time, TSS level, change, and change level

\begin{tabular}{|c|c|c|c|}
\hline & Placebo & Drug & $\mathbf{P}^{\mathbf{a}}$ \\
\hline \multicolumn{4}{|l|}{ Time } \\
\hline Before treatment & $7(6-9)$ & $7(5-9)$ & 0.702 \\
\hline $1^{\text {st }}$ visit & $5(4-7)$ & $3(2-5)$ & $<0.001$ \\
\hline $2^{\text {nd }}$ visit & $4(3-7)$ & $1(0-6)$ & $<0.001$ \\
\hline $\mathrm{P}^{\mathrm{b}}$ & 0.003 & $<0.001$ & \\
\hline $\begin{array}{l}\text { Multiple comparisons } \\
\text { Before treatment- } 1^{\text {st }} \text { visit } \\
\text { Before treatment- } 2^{\text {nd }} \text { visit } \\
1^{\text {st }} \text { visit- } 2^{\text {nd }} \text { visit }\end{array}$ & $\begin{array}{l}p=0.010 \\
p=0.018 \\
p=0.103\end{array}$ & $\begin{array}{l}\mathrm{p}=0.002 \\
\mathrm{p}=0.003 \\
\mathrm{p}=0.048\end{array}$ & \\
\hline \multicolumn{4}{|l|}{ TSS Change } \\
\hline $\begin{array}{l}\text { Before } \\
\text { treatment- } 1^{\text {st }} \text { visit }\end{array}$ & $-2(-3-0)$ & $-4(-7-3)$ & $<0.001$ \\
\hline Before treatment- $2^{\text {nd }}$ visit & $-3(-6-0)$ & $-6(-8-0)$ & 0.006 \\
\hline $1^{\text {st }}$ visit- $2^{\text {nd }}$ visit & $-1(-3-2)$ & $-2(-3-4)$ & 0.508 \\
\hline \multicolumn{4}{|l|}{ TSS Levels } \\
\hline Before treatment & $7(5-9)$ & $7(5-9)$ & 0.883 \\
\hline $1^{\text {st }}$ visit & $6(4-8)$ & $3(2-5)$ & $<0.001$ \\
\hline $\mathrm{P}^{\mathrm{b}}$ & 0.119 & 0.002 & $<0.001$ \\
\hline Before treatment- $1^{\text {st }}$ visit & $-2(-3-3)$ & $-4(-7-3)$ & \\
\hline
\end{tabular}

antergroup comparisons, bintragroup comparisons
Table 5: Comparison of the groups in terms of time, TBG level, change, and change level

\begin{tabular}{lccc}
\hline & Placebo & Drug & Pa $^{\mathbf{a}}$ \\
\hline Time & $3(3-3)$ & $3(3-3)$ & - \\
Before treatment & $3(2-3)$ & $2(1-3)$ & 0.009 \\
$1^{\text {st }}$ visit & $2(2-3)$ & $1(1-3)$ & 0.002 \\
$2^{\text {nd }}$ visit & 0.002 & $<0.001$ & \\
$\mathrm{P}^{\mathrm{b}}$ &
\end{tabular}

Multiple comparisons

Before treatment- ${ }^{\text {st }}$ visit $\quad \mathrm{p}=0.083 \quad \mathrm{p}=0.002$

Before treatment- $2^{\text {nd }}$ visit $\quad \mathrm{p}=0.005 \quad \mathrm{p}<0.001$

$1^{\text {st }}$ visit-2 $2^{\text {nd }}$ visit $\quad \mathrm{p}=0.025 \quad \mathrm{p}=0.035$

LBG change

Before treatment- $1^{\text {st }}$ visit $\quad 0(-1-0) \quad-1(-2-0) \quad 0.009$

Before treatment- $2^{\text {nd }}$ visit $\quad-1(-1-0) \quad-2(-2-0) \quad 0.002$

$1^{\text {st }}$ visit-2 $2^{\text {nd }}$ visit $\quad-1(-1-0) \quad-1(-2-1) \quad 0.917$

LBG levels

Before treatment $3(3-3) \quad 3(3-3) \quad 1$ t. 000

$1^{\text {st }}$ visit $\quad 3(2-3) \quad 2(1-3) \quad 0.003$

$\begin{array}{llll}\mathrm{P}^{\mathrm{b}} & 0.083 & 0.002 & 0.003\end{array}$

Before treatment- $1^{\text {st }}$ visit $\quad 0(-1-0) \quad-1(-2-0)$

antergroup comparisons, 'intragroup comparisons 
Table 6: Distribution of reproduction frequencies between groups based on time

\begin{tabular}{lccc}
\hline Groups & $\begin{array}{c}\text { Placebo } \\
(\mathbf{n = 9 )}\end{array}$ & $\begin{array}{c}\text { Drug } \\
(\mathbf{n = 1 2})\end{array}$ & $\mathbf{P}^{\mathbf{a}}$ \\
\hline Before treatment & $9(100 \%)$ & $12(100 \%)$ & - \\
$1^{\text {st }}$ visit & $9(100 \%)$ & $4(33.3 \%)$ & 0.005 \\
$2^{\text {nd }}$ visit & $9(100 \%)$ & $3(25.0 \%)$ & $<0.001$ \\
Multiple comparisons & $\mathrm{p}=1.000$ & $\mathrm{p}=0.008$ & \\
$\quad$ Before treatment- ${ }^{\text {st }}$ visit & $\mathrm{p}=1.000$ & $\mathrm{p}=0.004$ & \\
Before treatment-2 $^{\text {nd }}$ visit & $\mathrm{p}=1.000$ & $\mathrm{p}=1.000$ & \\
$1^{\text {st }}$ visit-2 & & \\
\hline
\end{tabular}

${ }^{\text {a Intergroup comparisons }}$

Table 7: Distribution of reproduction frequencies between groups based on time

\begin{tabular}{lccc}
\hline Groups & $\begin{array}{c}\text { Placebo } \\
(\mathbf{n = 1 1 )}\end{array}$ & $\begin{array}{c}\text { Drug } \\
(\mathbf{n = 1 2})\end{array}$ & $\mathbf{P}^{\mathbf{a}}$ \\
\hline $\begin{array}{l}\text { Before } \\
\text { treatment }\end{array}$ & $11(100 \%)$ & $12(100 \%)$ & - \\
$1^{\text {st }}$ visit & $11(100 \%)$ & $4(33.3 \%)$ & $<0.001$ \\
$\mathrm{P}^{\mathrm{b}}$ & - & $\mathrm{p}=0.008$ & \\
\hline
\end{tabular}

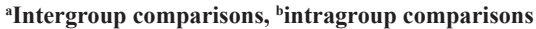

pessary application ( 2 pessaries every 3 days) to patients with bacterial vaginal infections, accompanied by candidiasis or not, or patients with only candidiasis. The patients decided that the treatment was good and very good by $91 \%$ for effectiveness and $99 \%$ for local tolerability [11]. Another study conducted in 2002 in a similar design to the present study, dequalinium chloride was tested in the treatment of vaginal infections associated with various etiologies, and the clinical effect and safety were compared by povidone-iodine vaginal pessaries. A total of 180 patients participated in the study, and it was found that its clinical effectiveness and tolerability were good, and its side effects were minimal by all patients and researchers [12]. Discharge and burning complaints were usually monitored to disappear within 24-72 $\mathrm{h}$. As a criterion for a full recovery, the TSS was planned to be 2 and below, and LBG was planned to be 1 . Once again, the fact that the agent pathogen that was initially reproduced in the last visit also could not be produced was the laboratory evidence of drug effectiveness. Similar to the result of the present study, a study by Büyükbayrak et al. found that dequalinium chloride was effective in fungal and bacterial infections compared to the time before treatment [10].

TSS is a subjective evaluation as it is the assessment of discharge, burning, and itching complaints made by the patient; therefore, it is an expected result that the values in the placebo group seemed to be improving. While none of the nine patients in the placebo group who could complete the study was able to reach the result of 2 and below TTS, which was the full recovery criteria (recovery $0 \%$ ); 11 patients of 12 patients in the drug group who could complete the study were able to reach this result (recovery $92 \%$ ). The study by Büyükbayrak et al. found a significant decrease in the bad smell, burning, itching, and dyspareunia compared to before treatment [10].

LBG is an objective criterion that shows lactobacilli dominance in the microscopic examination. The flora was evaluated as abnormal in case of very few or no lactobacilli (LBG III), disturbed in case of few lactobacilli (LBG II), or normal in case of lactobacilli dominance (LGB I), and LGB was planned to be I for full recovery criteria. While none of the nine patients in the placebo group who could complete the study was able to reach the result of LBG I (recovery $0 \%$ ); 11 patients of 12 patients in the drug group who could complete the study were able to reach this result (recovery $92 \%$ ). The study by Büyükbayrak et al. found a significant difference in the microbiological results compared to before treatment [10]. The most accurate criterion of whether patients benefited from drug or placebo during follow-up visits was whether there was any pathogenic agent reproduced as a laboratory. From this point of view, all nine patients in the placebo group who were able to complete the study had an agent pathogen, and there was no laboratory recovery $(0 \%)$. Of the 12 patients in the drug group who were able to complete the study, nine had no reproduction, according to which the recovery rate was $75 \%$. However, the fact that there was a different agent than the basic in the $2^{\text {nd }}$ visits of the remaining three patients (no: 5, 6 , and 14) while no reproduction occurred in their $1^{\text {st }}$ follow-up visits revealed a possibility of reinfection in these patients. In light of these assessments, all 12 patients in the drug group were considered to have recovered $(100 \%)$.

When all values were examined in total, as a result of the study, 12 of the 15 patients included in the study in the drug group completed the study, and 11 patients recovered according to the TTS criterion and the LBG criterion (92\%). Looking at the placebo group, 11 of the 15 patients participating in the study were able to reach the $1^{\text {st }}$ follow-up visit, and nine of them made it to the $2^{\text {nd }}$ check-up. None of these nine patients were able to go down to 2 or below in TTS nor did they reach the score of 1 in LBG $(0 \%)$.

The fact that $92 \%$ of the patients who participated in the study in total recovered are parallel to the other two studies in the literature $[10,12]$. However, when other studies were examined, it was seen that the parameters used as recovery criteria in the present study were not used all together and they were not conducted in a placebo-controlled manner $[10,12]$. The small number of patients is a limitation of this study. Another limitation is that the long-term (recurrence, etc.) effects of the drug have not been evaluated.

\section{CONCLUSION}

It was found that dequalinium chloride is effective for the treatment of aerobic vaginitis. However, studies containing a larger sample group, including the long-term effects (efficacy and side effects) of the drug, should be conducted to prove our conclusion.

\section{REFERENCES}

1. Ison CA. Factors affecting the microflora of lower genital tract of healthy women. In: Hill MJ, editor. Human Microbial Ecology. Boca Raton: CRC Press; 1990.

2. Schwebke JR, Richey CM, Weiss HL. Correlation of behaviours with microbiological changes in vaginal flora. J Infect Dis 1999;180:1632-6. 
3. Pybus V, Onderdonk AB. Microbial interactions in the vaginal ecosystem, with emphasis on the pathogenesis of bacterial vaginosis. Microbes Infect 1999;1:285-92.

4. Sobel JD. Desquamative inflammatory vaginitis: A new subgroup of purulent vaginitis responsive to topical 2\% clindamycin therapy. Am J Obstet Gynaecol 1994;171:1215-20.

5. Donders GG, Bellen G, Rezeberga D. Aerobic vaginitis in pregnancy. Int J Obstetr Gynaecol 2011;118:1163-70.

6. Gaspar C, Rolo J, Cerca N, et al. Dequalinium chloride effectively disrupts bacterial Vaginosis (BV) Gardnerella spp. Biofilms. Pathogens 2021;261:1-10.

7. Simpson T, Merchant J. Vaginal douching among adolescent and young women: More challenges than progress. J Pediatr Adolesc Gynecol 2004; $17: 249-55$.

8. Della Casa V, Noll H, Gonser S, et al. Antimicrobial activity of dequalinium chloride against leading germs of vaginal infections. Arzneimittelforschung 2002;52:699-705.

9. Mendling W, Weissenbacher ER, Gerber S, et al. Use of locally delivered dequalinium chloride in the treatment of vaginal infections: A review. Arch Gynecol Obstet 2016;293:469-84.
10. Büyükbayrak EE, Kaymaz Ö, Karşıdağ Y, et al. Dequalinium chloride is it an effective alternative for local treatment of vaginal infections? Gynecol Obstet Reprod Med 2012;18:16-20.

11. Strecker M, Kokemohr H, Teucher T, et al. Antisepti kagegen vulvovaginitiden. TW Gynakol 1993;6:409-12.

12. Peterson EE. Local treatment of vaginal infections of varying etiology with dequalinium chloride or povidone iodine. A randomised, doubleblind, active-controlled, multicentric clinical study. Arzneimittelforschung 2002;52:706-15.

Funding: None; Conflict of Interest: None Stated.

How to cite this article: Tekgunduz SE, Saracoglu F. Evaluation of the effectiveness of dequalinium chloride vaginal tablets in aerobic vaginitis: A placebo-controlled study. Eastern J Med Sci. 2021;6(3):50-56.

DOI: 10.32677/EJMS.2021.v06.i03.3090 